International Journal of Current Advanced Research

ISSN: O: 2319-6475, ISSN: P: 2319 - 6505, Impact Factor: SJIF: 5.995

Available Online at www.journalijcar.org

Volume 6; Issue 4; April 2017; Page No. 3222-3224

DOI: http://dx.doi.org/10.24327/ijcar.2017.3224.0230

\title{
CLINICAL STUDY OF DERMATOSES OF PREGNANCY
}

\author{
Vinita Gupta ${ }^{1}$ and PoonamTaneja ${ }^{2}$
}

${ }^{1}$ Department of Dermatology, SGT Medical College, Gurgaon

2Department of Gynaecology, SGT Medical College, Gurgaon

\section{A R T I C L E I N F O}

\section{Article History:}

Received $17^{\text {th }}$ January, 2017

Received in revised form $19^{\text {th }}$ February, 2017

Accepted $2^{\text {nd }}$ March, 2017

Published online $28^{\text {th }}$ April, 2017

\section{Key words:}

Pregnancy, Dermatoses, Skin

\begin{abstract}
A B S T R A C T
Background: During pregnancy profound immunologic, metabolic, endocrine and vascular changes occur resulting in both physiologic and pathologic changes in the skin and its appendages. These skin changes can be separated into three main categories: Hormone related, pre existing and pregnancy specific. Aim: The present study was conducted with an aim to find the clinical pattern and incidence of various skin changes of pregnancy. Methods: All pregnant females reporting to antenatal clinic of SGT Medical College and Hospital during the period of one year were included in this study. Results: A total of 341 pregnant women were enrolled in the present one year long study out of which 194 $(56.89 \%)$ were primigravidas and 147 (43.11\%) were multi gravidas. Maximum incidence of $78 \%$ was found in the age group between 15-25 years of age. Physiological changes were seen in all the pregnant females while dermatoses affected by pregnancy were reported in only $12.3 \%$ cases. Dermatoses specific for pregnancy were found in $7.9 \%$ cases. Conclusion: clinicians must be able to distinguish physiological changes of pregnancy from several other dermatoses that can present during the period of pregnancy in order to provide timely management and thus reducing maternal and fetal morbidity.
\end{abstract}

Copyright $₫ 2017$ Vinita Gupta and Poonam Taneja. This is an open access article distributed under the Creative Commons Attribution License, which permits unrestricted use, distribution, and reproduction in any medium, provided the original work is properly cited.

\section{INTRODUCTION}

Cutaneous changes and eruptions during pregnancy are exceedingly common and in some cases a cause for substantial anxiety on the part of the prospective mother. Some of these are benign and reversible after delivery whereas others can have potential effects on foetus in terms of morbidity and mortality.[1] Likewise, The concerns of the patient may range from cosmetic appearance, to chance of recurrence of the particular problem during a subsequent pregnancy, to its potential risks on fetus.[2] There are three general categories of pregnancy-associated skin conditions: 1) benign skin conditions from normal hormonal changes or physiological skin changes, 2) pre existing skin conditions that change during pregnancy or skin diseases affected by pregnancy, and 3) pregnancy specific dermatoses.[3] Physiological skin changes include striae gravidarum, hyper pigmentation and hair, nail and vascular changes. Pre existing skin conditions that may be affected by pregnancy include psoriasis, atopic dermatitis, candidal and other fungal infections, benign appendageal lesions and many more. True dermatoses of pregnancy include pruritic urticarial apples and plaques of pregnancy (PUPPP), prurigo of pregnancy, intrahepaticcholestasis of pregnancy, Pemphigus gestationis, impetigo Herpetiformis and pruritic folliculitis of pregnancy.

*Corresponding author: Vinita Gupta

Department of Dermatology, SGT Medical College, Gurgaon

\section{MATERIALS AND METHODS}

The study comprised of all pregnant females reporting to antenatal clinic of SGT Medical College and Hospital during the period between January 2015 to December 2015 were included in this study. A total of 346 pregnant women were included in the study. Informed consent was obtained before before the interview and clinical examination. All patients were subjected to detailed history and thorough clinical examination to note all the physiological and pathological mucocutaneous changes. Routine blood, urine and stool examination, and screening with VDRL and ELISA for HIV was done in all cases. In patients with white discharge, a $\mathrm{KOH}$ mount, saline mount and gram stain were done.

\section{RESULTS}

A total of 341 pregnant females were included in the one year study conducted between January 2015 to December 2015. Patients were divided in age groups between $15-25$ years (266 cases, 78\%) and 26-40years (75 cases, 22\%). Of these 194 $(56.89 \%)$ females were primigravidas and 147 (4.11\%) were multi gravidas. Most of them presented in their third trimester $(222,65.1 \%)$ followed by second $(75,22 \%)$ and first trimester $(44,12.9 \%)$. Pruritus was the commonest symptom reported accounting for $18.2 \%$ (62) of the patients, followed by white discharge per vagina $(21,6.1 \%)$, while few complained of presence of one or other type of skin lesions due to dermatoses which were broadly divided into three categories: 
Physiological cutaneous changes Skin diseases (Pre existing or newly occurring) affected by pregnancy Pregnancy specific dermatological disorders Physiological changes were seen in $100 \%$ of cases, while dermatoses modified by pregnancy were observed in $12.3 \%$ cases and only $7.9 \%$ had dermatoses specific for pregnancy. Among the physiological changes, most common were the pigmentary changes including lineanigra, areolar pigmentation and melasma followed by connective tissue changes mainly including striae gravidarum.[Table 1]

Table 1 physiological changes of pregnancy

\begin{tabular}{|c|c|c|}
\hline Diseases * & No. Of Cases & Percentage \\
\hline \multicolumn{3}{|l|}{ Hyperpigmentation } \\
\hline Lineanigra & 291 & $85.3 \%$ \\
\hline Areolar hyperpigmentation & 280 & $82.1 \%$ \\
\hline Melasma & 34 & $10 \%$ \\
\hline Nevi darkening & 2 & $0.58 \%$ \\
\hline Recent scar pigmentation & 1 & $0.29 \%$ \\
\hline Pigmentary demarcation lines & 1 & $0.29 \%$ \\
\hline \multicolumn{3}{|l|}{ Connective tissue changes } \\
\hline Striae gravidarum & 299 & $87.68 \%$ \\
\hline Skin tags & 9 & $2.64 \%$ \\
\hline \multicolumn{3}{|l|}{ Vascular changes } \\
\hline Edema & 122 & $35.78 \%$ \\
\hline Gingivitis & 21 & $6.15 \%$ \\
\hline Varicosities & 4 & $1.17 \%$ \\
\hline Palmar erythema & 4 & $1.17 \%$ \\
\hline Spider Nevi & 2 & $0.59 \%$ \\
\hline Vulval edema & 1 & $0.29 \%$ \\
\hline \multicolumn{3}{|l|}{ Hair changes } \\
\hline Male pattern alopecia & 4 & $1.17 \%$ \\
\hline Hirsuitism & 2 & $0.58 \%$ \\
\hline Increased hair growth & 2 & $0.58 \%$ \\
\hline \multicolumn{3}{|l|}{ Nail changes } \\
\hline Brittleness & 6 & $1.76 \%$ \\
\hline Transverse grooving & 3 & $0.88 \%$ \\
\hline Sub ungual hyper keratosis & 1 & $0.29 \%$ \\
\hline Onycholysis & 1 & $0.29 \%$ \\
\hline \multicolumn{3}{|l|}{ Glandular changes } \\
\hline Acne & 32 & $9.38 \%$ \\
\hline Montgomery tubercles & 22 & $6.45 \%$ \\
\hline
\end{tabular}

* more than one dermatoses were present in many cases

Candidal vaginitis $(13,3.81 \%)$ was found to be the most common dermatosis affected by pregnancy closely followed by acne vulgaris $(9,2.64 \%)$ and eczemas $(6,1.76 \%)$. [Table 2]

Table 2 Dermatoses affected by pregnancy

\begin{tabular}{ccc}
\hline Disease & No. Of Cases & Percentage \\
\hline Candidal vaginitis & 13 & $3.81 \%$ \\
T.corporis & 3 & $0.88 \%$ \\
Eczema & 6 & $1.76 \%$ \\
Psoriasis & 2 & $0.59 \%$ \\
Acne vulgaris & 9 & $2.64 \%$ \\
Veruccavulgaris & 1 & $0.29 \%$ \\
Condylomata acuminata & 1 & $0.29 \%$ \\
Herpes genitalis & 2 & $0.69 \%$ \\
Herpes zoster & 2 & $0.59 \%$ \\
Skin tags & 9 & $2.64 \%$ \\
Milia en plaque & 1 & $0.29 \%$ \\
Urticaria & 2 & $0.59 \%$ \\
\hline
\end{tabular}

Table 3 pregnancy specific dermatoses

\begin{tabular}{ccc}
\hline Diseases & No. Of Cases & Percentage \\
\hline PUPPP & 19 & $5.57 \%$ \\
Pruritus gravidarum & 4 & $1.17 \%$ \\
(intrahepaticcholestasis of pregnancy) & 12 & $3.52 \%$ \\
Prurigo of pregnancy & 1 & $0.29 \%$ \\
Pemphigus gesattionis & 1 & $0.29 \%$ \\
\hline Pruritic folliculitis of preganncy & &
\end{tabular}

Total of 37 females were diagnosed of pregnancy specific dermatoses of which $19(5.57 \%)$ had PUPPP (pruritic urticarial papules and plaques of pregnancy). [Table 3]

\section{DISCUSSION}

Pruritus was reported to be the commonest symptom with incidence of $18.2 \%$ in the present study. According to Winton et al, pruritus from all cases may occur in $17 \%$ of pregnant women,[4] while Wong et al and Roger et al reported incidence of pruritus in $20 \%$ and $18 \%$ respectively. $[5,6]$ Candidal vaginitis was found to be the most common cause for vaginal discharge. That monilial vaginitis is 10 to 20 times more common during pregnancy has been supported by Winton et al and Dotz et al.[1,7]

Physiological changes were seen in all the pregnant females. Several other studies have reported physiological changes in upto $100 \%$ cases.[8,9] Pigmentary changes were noticed in all the cases.[3] Striae were found to be the commonest physiological change $(87.68 \%)$ closely followed by Lineanigra (85.3\%)and areolar hyper pigmentation $(82.1 \%)$ [Fig 2]. Other less commonly encountered physiological changes were melasma, gingivitis, acne, montgomery tubercles, hair and nail changes.

The most common physiological changes are pigmentary alterations, stretch marks, vascular spiders and telogen effluvium.[10] Pigmentary changes occurred in $98.82 \%$ of the patients.[11] Similar incidences have been reported by other authors.[4,5,7] Incidence of melasma was reported to be $10 \%$ similar to the finding of V. Shivakumar and Raj et al.[11,12] In our study, striae gravidarum were seen in $299(87.68 \%)$ cases. Few studies have shown incidences between 60 to $80 \%$ $[8,9,11,12]$ while others have reported incidences upto $90 \% \cdot[1,5,7]$

Montgomery's tubercles is well known during pregnancy in $30-50 \%$ of pregnant women. [10] In our study, Montgomery's tubercles were seen in $22(6.45 \%)$ cases. This was found to be consistent with other studies. [13] Vascular changes result from distension, instability and proliferation of vessels [4] and were seen in $45.16 \%$ of cases. Non pitting edema over the hands, feet and face was observed in $35.78 \%$ cases. Muzaffer et al [8] reported edema in 48.5\% whereas Rashmi et al [9] reported it in $9.8 \%$. Varicosities were seen in $1.17 \%$ comparable to other studies. $[8,12]$

Gingivitis may occur in upto $100 \%$ of pregnant women with varying degree of severity.[5] 6.15\% cases of gingivitis were reported. A bit higher percentage has been reported by other authors.[8,13] PUPPP (also known as polymorphic eruption of pregnancy) was the commonest specific disorder of pregnancy accounting for $5.57 \%$ followed by prurigo of pregnancy with $12(3.52 \%)$ cases and pruritus gravidarum (also known as intrahepaticcholestasis of pregnancy) with 4 $(1.17 \%)$ cases. Similar to our study, PUPPP was reported as commonest specific dermatoses of pregnancy in study by Kumari R [9] accounting for $63.6 \%$ cases followed by pruritus gravidarum while Shivakumar and Madhavamurthy [11] reported prurigo of pregnancy as the commonest specific dermatoses of pregnancy with incidence of $9.41 \%$ followed by pruritus gravidarum. 


\section{CONCLUSION}

To conclude, a variety of cutaneous lesions can be seen in pregnant women which need a meticulous examination and investigations to reach a correct diagnosis enabling careful management in an effort to minimise maternal and foetal morbidity.

\section{Referances}

1. Kroumpouzos G, Cohen LM. Dermatoses of pregnancy. J Am Acad Dermatol 2001; 45:1-19. [PUBMED] [FULLTEXT]

2. Lawley TJ, Yancey KB. Skin changes and diseases in pregnancy. In: Freedberg IM, Eisen AZ, Wolff K, Austen KF, Goldsmith LA, Katz SI, et al , editors. Fitzpatrick's Dermatology in general medicine. 5th ed. McGraw-Hill: New York; 1999. p. 1963-9.

3. Marc Tunzi, Gary R. Gray. Am Fam Physician. 2007 Jan 15;75(2):211-218.

4. Winton GB, Lewis CW. Dermatoses of pregnancy. $J$ Am Acad Dermatol 1982; 6:977-998. [PUBMED] [FULLTEXT]

5. Wong RC, Ellis CN. Physiologic skin changes in pregnancy. J Am Acad Dermatol 1984; 10:929-940. [PUBMED] [FULLTEXT]
6. Roger D, Vaillant L, Fognon A, et al. Specific pruritic diseases of pregnancy. Arch Dermatol 1994; 130:734739.

7. Dotz W, Berman B. Dermatologic problems of pregnancy. In: Cherry SH, Merkatz IR, editors. Complications of Pregnancy: Medical Surgical Gynaecologic Psychosocial and Perinatal, 4th ed. Baltimore: Williams and Wilkins, 1991:562-587. Back to cited text no. 6

8. Muzaffar F, Hussain I, Haroon TS. Physiologic skin changes during pregnancy: A study of 140 cases. Int $J$ Dermatol 1998;37:429-31.[PUBMED]

9. Kumari R, Jaisankar TJ, Thappa DM. A clinical study of skin changes in pregnancy. Indian $J$ Dermatol VenereolLeprol 2007; 73:141.

10. Martin AG, Leal-Khouri S. Physiological skin changes associated with pregnancy. Int J Dermatol 1992; $31: 375-8$

11. Shivakumar V, Madhavamurthy P. Skin in pregnancy. Indian J Dermatol VenereolLeprol 1999; 65:23-5.

12. Raj S, Khopkar V, Kapasi A, et al. Skin in pregnancy. Indian J Dermatol VenereolLeprol 1992; 58:84-88.

13. Rathore SP, Gupta S, Gupta V. Pattern and prevalence of physiological cutaneous changes in pregnancy: A study of 2000 antenatal women. Indian J Dermatol VenereolLeprol 2011; 77:402.

\section{How to cite this article:}

Vinita Gupta and PoonamTaneja (2017) ' Clinical Study Of Dermatoses Of Pregnancy', International Journal of Current Advanced Research, 06(04), pp. 3222-3224.

DOI: http://dx.doi.org/10.24327/ijcar.2017.3224.0230 